\title{
Espartanos e atenienses na escola: da filologia clássica à educação nacional nos Estados modernos europeus
}

\author{
Rafael Guimarães Tavares da Silva ${ }^{1}$ \\ ORCID: 0000-0002-8985-8315
}

\section{Resumo}

No período de consolidação dos Estados Nacionais europeus industrializados, principalmente no fim do século XIX e início do século XX, os estudos clássicos foram incorporados ao modelo educacional responsável pela formação patriótica de seus futuros cidadãos. Refletindo acerca dessa dimensão educativa e política, vários classicistas do período voltaram suas pesquisas para uma compreensão dos modelos pedagógicos aplicados pelas bem-sucedidas civilizações antigas (como a Atenas ou a Esparta do período clássico) a fim de propor novos caminhos para os desafios do presente: dessa forma se dão a ler algumas das reflexões de Girard (1889), Wilamowitz-Moellendorf (1901; 1914-5), Freeman (1907) e Jaeger (2013). Esse impulso pedagógico esteve intimamente ligado às conjunturas sóciopolíticas da época - responsáveis, inclusive, pelo movimento que culminou nas duas Guerras Mundiais, entre 1914 e 1945. Cumpre lembrar que formas violentas de controle estatal, manifestadas principalmente enquanto prerrogativas policiais e carcerárias, unidas a formas mais sutis de poder - por meio da educação obrigatória, por exemplo -, estão entre os fatores que contribuíram para um acirramento das tensões entre os Estados Nacionais na época. Tal como sugerido pelos estudos de Luciano Canfora, François Hartog e Suzanne Marchand, a filologia clássica acabou se revelando um front entre os muitos outros que entraram em disputa nesse complicado período histórico. 0 objetivo deste artigo é compreender esse processo e suas consequências para o desenvolvimento do campo dos estudos clássicos.

\section{Palavras-chave}

Recepção clássica - Educação - História dos estudos clássicos.

1- Universidade Federal de Minas Gerais, Belo Horizonte, MG, Brasil. Contato: gts.rafa@hotmail.com.

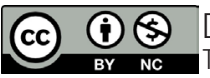

DOI: http://dx.doi.org/10.1590/S1678-4634201945210672 


\section{Spartans and Athenians in the school: from Classical Philology to National Education in the modern European States}

\section{Abstract}

In the period of consolidation of the industrialized European nation states, especially in the late $19^{\text {th }}$ early $20^{\text {th }}$ centuries, classical studies were incorporated into the educational model responsible for the patriotic formation of their future citizens. Reflecting on this educational and political dimensions, several classicists of the period turned their research to an understanding of the pedagogical models applied by successful ancient civilizations (such as classical Athens or classical Sparta) in order to propose new avenues for the challenges of the present: thus they turn to the reflections by Girard (1889), WilamowitzMoellendorf (1901, 1914-5), Freeman (1907) and Jaeger (2013). This pedagogical impulse was closely linked to the socio-political conjunctures of the time, including the movement that culminated in the two World Wars between 1914 and 1945. It should be remembered that violent forms of state control, manifested mainly as prerogatives of police and prison, together with more subtle forms of power - through compulsory education, for example - are factors that have contributed to the intensification of tensions among the National States at the time. As the studies by Luciano Canfora, François Hartog, and Suzanne Marchand suggest, classical philology has turned out to be a major cultural front among the many which came into contention in this complicated historical period. The aim of this article is to understand this process and its consequences for the development of the field of classical studies.

\section{Keywords}

Classical reception - Education - History of classical studies.

0 campo de estudos conhecido como recepção clássica é relativamente recente no interior dos estudos clássicos, posto que está intimamente ligado ao movimento de teoria da recepção, iniciado desde fins da década de 1960 com Hans-Robert Jauss, Wolfgang Iser, Roland Barthes e Stanley Fish, entre outros. Apesar de não ter acontecido há muito tempo, essa mudança de paradigma representa um considerável alargamento do horizonte epistemológico que antes era característico dos trabalhos sobre a tradição clássica, tal como emblematicamente representados pelo célebre livro de Gilbert Highet (1976 [1949]), The classical tradition [A tradição clássica]. Abandonando - pelo menos em parte - a perspectiva sugerida por uma pretensa primazia cronológica e axiológica da cultura clássica, os estudos de recepção clássica oferecem a possibilidade de se abordar, sob um viés consideravelmente menos marcado pelo colonialismo, uma multiplicidade de fenômenos culturais, tais como os relativos à recepção por meio da tradução, do teatro, do cinema e até mesmo da política. 
Os vários artigos do livro organizado por Lorna Hardwick e Christopher Stray (2008), A companion to classical receptions [Um compêndio para recepções clássicas], indicam bem as possibilidades atualmente abertas a esse campo de estudos.

Gostaria de destacar uma dimensão particularmente emblemática dessa longa história da recepção clássica: o emprego dos estudos clássicos para o desenvolvimento de uma nova educação durante o período de formação e consolidação dos Estados Nacionais europeus industrializados, especificamente na França, no Reino Unido e na Alemanha. Esse fenômeno de apropriação e cooptação dos estudos clássicos com fins políticos e práticos é bastante complexo e multiforme, mas pretendo apenas indicar suas principais linhas de força que um primeiro contato com algumas das fontes do período - sob orientação dos apontamentos oferecidos por estudiosos contemporâneos - parece sugerir.

Se fosse necessário remontar à arkh [origem; princípio; poder] da relação entre estudos clássicos e educação, inevitavelmente teríamos que começar com os escritos da própria Antiguidade, pois muitos autores antigos já teorizavam sobre isso, como sugerem certas reflexões de, por exemplo, Platão, Aristóteles, Cícero e Quintiliano (HARTOG, 2003, p. 118-122). Contudo, como nosso escopo é a educação a partir do período de industrialização dos principais Estados Nacionais europeus, um bom ponto de partida é a ruptura histórica representada pela Revolução Francesa, a partir das ideias propostas por autores do Iluminismo, e seus desdobramentos para a modernidade europeia.

Tal como sugerido por Luciano Canfora (1980, p. 11) e François Hartog (2003, p. 142), os jacobinos - mesmo os mais radicais dentre eles - empregaram constantemente uma retórica classicizante, buscando retomar uma série de lugares-comuns do discurso antigo, com o objetivo de propor uma renovação do imaginário relativo à realidade presente. Nesse sentido, seja por meio de uma retomada da Esparta de Licurgo, seja por alusões à formação da República Romana (com a expulsão da realeza), a Antiguidade que então se evocava representava um momento de ruptura (HARTOG, 2003, p. 144). Tal estratégia retórica, contudo, não deixa de apresentar contradições, como pode indicar a limitada abrangência da ideia de igualdade numa Esparta comandada por uma elite de algumas centenas de nobres guerreiros (os únicos considerados de fato homoioi [semelhantes]) ou mesmo numa república romana dominada em larga medida pelas elites que compunham o senado e os cargos públicos de maior poder social.

Da idealização algumas vezes ingênua das "Repúblicas antigas", da "imediata" identificação com a Antiguidade grega e romana por parte do pessoal dirigente da Revolução, certamente é responsável - em medida não negligenciável - o conhecimento retórico, unilateral e simplesmente insatisfatório daquele mundo, especialmente do mundo grego. (CANFORA, 1980, p. 12). ${ }^{2}$

As principais obras sobre a Antiguidade a que tinham acesso os franceses do período eram aquelas da autoria do abade de Mably e, ainda mais, as de Jean-Jacques Rousseau. A fascinação que os antigos exerciam sobre esses autores é notável em muitas

2- Tradução minha. No original: "Della idealizzazione talora ingenua delle «Repubbliche antiche», della 'immediata' identificazione con l'antichità greca e romana da parte del personale dirigente della Rivoluzione, è certo responsabile, in misura non trascurabile, la conoscenza rettorica, unilaterale e senz'altro insoddisfacente, di quel mondo, in ispecie del mondo greco." (CANFORA, 1980, p. 12). 
de suas obras, como nas Observations sur les Grecs [Observações sobre os gregos] (1749) e nas Observations sur les Romains [Observações sobre os romanos] (1751), de autoria do primeiro, e na descrição da cidade do Contrat social [Contrato social] (1762) e no esboço de uma Histoire de Lacédémone [História da Lacedemônia], do segundo. Em todo caso, é o filtro imposto por esse viés fascinado com a Antiguidade que tornou possível uma passagem como a seguinte, no início de um discurso inflamado de Robespierre, num momento bastante delicado da Convenção, a 7 de maio de 1794:

0 mundo moral, muito mais ainda do que o mundo físico, parece cheio de contrastes e enigmas. A natureza mostra-nos que o homem nasceu para a liberdade e a experiência dos séculos mostranos o homem escravo; seus direitos estão escritos em seu coração e sua humilhação, na história: a espécie humana respeita Catão e se curva sob o jugo de César; a posteridade honra a virtude de Bruto, mas ela só a admite na história antiga; os séculos e a terra são uma partilha do crime e da tirania; a liberdade e a virtude mal repousaram um instante em alguns lugares do globo: Esparta brilha como um raio nas trevas imensas.

Não diga, contudo, Bruto, que a virtude é um fantasma! E vocês, fundadores da república francesa, não percam as esperanças na humanidade e não duvidem por um só momento do sucesso de sua grande empreitada! (ROBESPIERRE, 1867, p. 309). ${ }^{3}$

0 destino reservado aos jacobinos e à sua tentativa de encontrar na Antiguidade os modelos para uma ação revolucionária radical bem-sucedida, contudo, veio a ser a derrota. Nesse sentido, é emblemático que um termidoriano como Constantin Volney discursando na École Normale Supérieur [Escola Normal Superior], pouco após a queda de Robespierre - já apontasse a contradição de se tentar constituir um ideal de liberdade com base em algum exemplo extraído da Antiguidade: seja Esparta, onde uma multidão de escravos hilotas era massacrada sob o jugo feroz dos senhores lacedemônios; seja Atenas, onde um regime de escravidão igualmente difundido era em larga medida responsável pelo ócio do cidadão livre; seja a Roma republicana, onde fundamentalmente a mesma forma de organização social também vigorava em favor de uma minoria. ${ }^{4}$

Esse tipo de correção à leitura que os jacobinos tentaram fazer da própria Revolução à luz de modelos antigos tornou-se um fenômeno recorrente na produção literária francesa posterior, como indicam os escritos de Madame de Staël, Benjamin Constant e, ainda mais tarde, Fustel de Coulanges (HARTOG, 2003, p. 145). Na célebre conferência pronunciada por Constant em Paris em 1819, "De la liberté des anciens comparée a celle des modernes" ["Da liberdade dos antigos comparada à dos modernos"], essa correção aparece de forma evidente, na medida em que o autor contrapõe a noção de liberdade dos antigos àquela

3- Tradução minha. No original: "Le monde moral, beaucoup plus encore que le monde physique, semble plein de contrastes et d'énigmes. La nature nous dit que l'homme est né pour la liberté, et l'expérience des siècles nous montre l'homme esclave; ses droits sont écrits dans son cœur, et son humiliation dans l'histoire: le genre humain respecte Caton, et se courbe sous le joug de César; la postérité honore la vertu de Brutus, mais elle ne la permet que dans l'histoire ancienne; les siècles et la terre sont le partage du crime et de la tyrannie; la liberté et la vertu se sont à peine reposées un instant sur quelques points du globe: Sparte brille comme un éclair dans des ténèbres immenses.

Ne dis pas cependant, ô Brutus, que la vertu est un fantôme! Et vous, fondateurs de la république française, gardez-vous de désespérer de I'humanité, ou de douter un moment du succès de votre grande entreprise!"

4- 0 trecho desse discurso, citado em tradução para o italiano, é referenciado e analisado por Canfora (1980, p. 16-19). 
que deveria figurar entre os modernos, sugerindo que seria um erro fatal confundir essas noções e suas especificidades. Essa compreensão é responsável por marcar profundamente a relação que a França viria a desenvolver com os clássicos ao longo de grande parte dos séculos XIX e XX, pois, desconfiando que o emprego da Antiguidade como modelo para o presente constituiria o erro responsável pela brutalidade do Terror, os intelectuais franceses permaneceriam reticentes com relação a qualquer tentativa de se instituir uma política apoiada em modelos antigos ao longo do futuro próximo. Contudo, "[n]o resto da Europa, as tradições alemã, inglesa e italiana, respondendo a outros interesses, iriam organizar-se diferentemente" (HARTOG, 2003, p. 149).

Na Inglaterra, a publicação dos múltiplos volumes da História da Grécia (18461856), de Georges Grote, tornava possível uma relação menos conflituosa entre o presente e a Antiguidade. Tal como sugerido por Hübscher (2016, p. 182), "[v]inculando a história política à história intelectual, o banqueiro e historiador britânico buscava estabelecer, através de um exame rigoroso das evidências, uma relação entre democracia e progresso intelectual, abordando a história grega a partir de uma perspectiva liberal." Nesse sentido, a democracia ateniense revelava-se uma espécie de prefiguração e fonte de inspiração para os ingleses e o império marítimo que eles estabeleceram ao longo do século XIX. Assim sendo, a Atenas clássica já traria aquilo mesmo que viria a constituir os pilares do próprio ideal inglês, "as origens do governo democrático, os princípios da liberdade de pensamento e da investigação racional” (HARTOG, 2003, p. 151).

$\mathrm{Na}$ Alemanha, contudo, a função modelar que os antigos viriam a desempenhar na educação moderna é a mais diametralmente oposta àquela que teve lugar na França (tanto durante a Revolução quanto no período da Restauração). 0 movimento intelectual iniciado por Winckelmann, mas levado a cabo principalmente por Schiller, Schleiermacher e Humboldt, culminou no projeto daquilo que viria a se tornar o modelo hegemônico de universidade moderna. Não é possível delinear aqui os meandros desse complexo desenvolvimento intelectual, ${ }^{5}$ mas o processo pode ser compreendido em linhas gerais da seguinte forma: em reação aos Estados absolutistas, às apropriações da Revolução Francesa e às reações advindas com o período da Restauração, elaborou-se um "mito grego alemão [der deutsche Griechenmythos]" - tomando por base principalmente as referências literárias clássicas -, que foi responsável por se sobrepor ao mito grego europeu e se transformar em um mito especificamente alemão, nacional, acerca da superioridade cultural da Alemanha (tal como se dá a ver nas obras de Herder, Schlegel e Humboldt). Assim sendo,

[o] parentesco com a nação eleita dos gregos antigos elevava os próprios alemães ao posto de uma nação eleita, nação no sentido de Kulturnation. Nesse contexto, a multiplicidade dos Estados e estruturas estatais na Alemanha não era considerada um fenômeno negativo, mas, pelo contrário, a condição da superioridade nacional no plano cultural. Essa primeira etapa é a do Neuhumanismus [novo humanismo] que afirma a identidade profunda entre alemães e gregos antigos. Para Wilhelm von Humboldt, que por suas reformas do ensino secundário e superior na

5- Para detalhes, (cf. READINGS, 1996, p. 62-69; HÜBSCHER, 2016, p. 19-32). 
Prússia (1809-1810) e pela fundação da Universidade de Berlim, em 1810, marcou longamente a vida cultural alemã, essa identificação com a Grécia clássica não tinha, em um primeiro momento, por finalidade a nação e a consciência nacional, mas a ideia de que a cultura grega e a cultura alemã - e mais precisamente a deutsche Klassik - eram a encarnação (Verkörperung) das potencialidades mais altas da humanidade. (BRUHNS, 2005, p. 23-4). ${ }^{6}$

Essa concepção universalista, contudo, servia muito bem aos propósitos políticos do florescente Estado Nacional da Prússia, em sua gradual ascendência sobre as demais regiões de língua e cultura alemãs. Defendendo a necessidade de se estabelecer uma relação de continuidade com a tradição - principalmente com essa tradição fictícia que passava a ser incorporada como a arkhế espiritual dos alemães, i.e., a Antiguidade helênica -, o modelo educacional da Alemanha e sua inspiração filosófica evitavam, a um só tempo, as consequências políticas da apropriação que a Revolução Francesa fizera da Antiguidade e a reação que autores termidorianos e do período da Restauração propuseram a tal forma de lidar com o passado. Ao invés de serem guiados pelo ditado de Mirabeau, segundo o qual, "para reconstruir tudo, era preciso demolir tudo [pour tout reconstruire, il fallait tout démolir]", os clássicos na Alemanha instituíam uma relação de continuidade com o presente, algo que se revelaria bastante proveitoso para o poder do Estado prussiano: a educação alemã - apoiada nos clássicos - passava a existir para produzir razão sem revolução e sem destruição (READINGS, 1996, p. 64).

Tal como demonstrado por Hinnerk Bruhns (2005, p. 21-43), os mais diversos aspectos da Antiguidade se prestaram às pesquisas e aos interesses dos estudiosos alemães desse período: desde a liberdade de que desfrutava cada pólis grega, no período clássico, em paralelo com os principados alemães do século XVIII e início do século XIX (com Humboldt), passando pela unificação grega sob o poder macedônico, em paralelo com a futura unificação alemã sob o poder prussiano (com Droysen), até o poderio do Império Romano, que, interpretado à luz das experiências políticas alemãs, surgia como o verdadeiro modelo de perfeição do Estado (com Mommsen). Por mais que a segunda metade do século XIX tenha testemunhado um movimento gradual de despolitização das Altertumwissenschaften [Ciências da Antiguidade], devido ao fortalecimento de uma aspiração cientificista interessada em interpretar os diversos momentos históricos a partir deles mesmos, sem aplicabilidade direta ou poder de evocação para alguma discussão contemporânea, ${ }^{7}$ é certo que a própria história da constituição desse campo de estudos na Alemanha dava margem ao tipo de apropriação que um período de crise viria a suscitar nesse país.

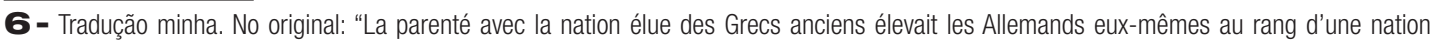
élue, nation au sens de Kulturnation. Dans ce contexte, la multiplicité des États et structures étatiques en Allemagne n'était pas considérée comme un phénomène négatif mais, au contraire, comme la condition de la supériorité nationale au plan culturel. Cette première étape est celle du Neuhumanismus qui affirme l'identité profonde entre Allemands et Grecs anciens. Pour Wilhelm von Humboldt, qui par ses réformes de l'enseignement secondaire et supérieur en Prusse (1809-1810) et par la fondation de l'Université de Berlin, en 1810, a marqué durablement la vie culturelle allemande, cette identification à la Grèce classique n'avait pas, dans un premier temps, pour finalité la nation et la conscience nationale, mais l'idée que la culture grecque et la culture allemande, plus précisément la deutsche Klassik, étaient l'incarnation (Verkörperung) des potentialités optimales de l'humanité."

7- Para detalhes desse processo, conferir Hübscher (2016, p. 26-44). 
Esse quadro bastante sucinto indica, em linhas gerais, de que forma alguns dos principais Estados Nacionais europeus concebiam sua complexa relação com a herança clássica no período em que a industrialização e a modernização se tornavam incontornáveis palavras de ordem na Europa. Se o trauma da Revolução Francesa deixara suas marcas na forma como a Europa - e, mais especificamente, a França - lidava com essa herança clássica, os atritos e conflitos advindos da corrida imperialista viriam a modificar essa relação de maneira ainda mais profunda: os Estados envolvidos nessa corrida passavam a cooptar a tradição clássica não apenas para se demarcarem uns dos outros, mas para desfrutarem de uma prerrogativa histórica e espiritual sobre os demais. Nesse sentido, pode ser instrutivo acompanhar a formulação que certos classicistas desses Estados elaboraram nesse período sobre alguns modelos pedagógicos aplicados pelas bem-sucedidas civilizações antigas (como a Atenas ou a Esparta do período clássico).

A obra de Paul Girard, L'Éducation athénienne au $V^{e}$ et au $I V^{e}$ siècle avant J.-C. [A educação ateniense nos séculos $V$ e IV a.C.], premiada pela Académie des inscriptions et belles-lettres [Academia das inscrições e belas-letras] e publicada em 1889, apresenta um caso interessante. Sugerindo certa identificação entre uma espontaneidade que seria característica dos atenienses clássicos e algo típico dos franceses, Girard (1889, p. 258259) defende uma educação espontânea e livre, de base evidentemente rousseauniana, na qual as capacidades intelectuais seriam desenvolvidas a partir da ação e dos interesses pessoais. Em seu estudo, nota-se, portanto, não apenas uma contraposição a um modelo educacional rígido e impositivo - como era característico do final do século XIX na Europa de modo geral $-{ }^{8}$ mas a proposição de que esse modelo devesse ser adotado no mais ateniense dos Estados europeus, isto é, na França da Terceira República. Segundo um estudioso francês contemporâneo,

[u]ma certa repolitização tornaria a acontecer na França apenas com a Terceira República, por meio da tese do "milagre grego". Estético a princípio, este se politizou a ponto de designar quase exclusivamente a democracia ateniense, com a qual se foi levado a identificar-se tanto mais de bom grado quanto mais se via surgir, na outra margem do Reno, o que não cabe chamar senão de uma "nova Esparta”. (HARTOG, 2003, p. 153).

Cumpre observar que, com o fito de oferecer uma imagem idealizada da Atenas clássica, concebida como contraposição à Esparta que servia de modelo ao militarismo defendido pelo Império Prussiano de Bismarck, ${ }^{9}$ o estudioso francês não se furtaria

\footnotetext{
8- Que se leve em conta um trecho como o seguinte: "Si maintenant on considère la manière dont était formée, dans les écoles et les gymnases, la jeunesse athénienne, on reconnaîtra que nul système n'était plus sage ni mieux approprié à la nature des jeunes gens. Laissons de côté cet heureux équilibre que savent maintenir les Athéniens entre les exercices du corps et ceux de l'esprit: cette harmonie bienfaisante ne leur est pas particulière; elle se retrouve ailleurs, elle est le principe même sur lequel repose l'éducation grecque. [...] Mais ce qui distingue Athènes, c'est la mesure qu'elle apporte dans toutes les épreuves auxquelles elle soumet l'enfant. [...] L'éducation, en tout, fuit les extrêmes; elle a plus à coeur de produire d'harmonieux ensembles que d'étonnantes, mais étroites spécialités; son but est de faire des hommes, non des prodiges, et dans ce dessein parait la haute idée qu'elle a de ses devoirs." (GIRARD, 1889, p. 330).

9 - Para mais detalhes, conferir Roche (2012). Na conclusão de seu estudo, a autora afirma o seguinte: "In general terms, we can see that, during the nineteenth century, the Spartan paradigm - often portrayed as representative of ancient Greece as a whole - was repeatedly adduced as a useful model for emulation by the Prussian military, in many different contexts. Such claims base their authority sometimes on 'facts' which
} 
Rafael Guimarães Tavares da SILVA

sequer a cometer certos deslizes de uma perspectiva histórica. A derrota ateniense na Guerra do Peloponeso, por exemplo, parece ser deliberadamente esquecida por Girard quando ele propõe o seguinte comentário - de tom evidentemente exortativo - na conclusão de seu estudo:

A história de Atenas, do início ao fim, é apenas um longo e esplêndido triunfo da juventude. Com esses sentimentos, os atenienses não podiam obrigar a criança à severa disciplina que se lhe impunha em outros lugares e, nem nos estudos nem na conduta, exigiam dela uma obediência que julgavam incompatível com seu caráter. Eis o que faz com que a educação nos apareça, junto deles, marcada por tal doçura. 0 estudante trabalha, mas livremente; seus mestres contentam-se com a indicação do que deve fazer: cabe a ele exercer-se nisso. Nem o ginásio nem a escola são para ele prisões sombrias onde seria preciso cumprir, em um tempo dado, uma tarefa fixa. (GIRARD, 1889, p. 331). ${ }^{10}$

$\mathrm{Na}$ Inglaterra, por outro lado, a tradição liberal e democrática que caracterizou seu discurso ao longo do século XIX, levando-a a identificar-se principalmente com a Atenas clássica (ou antes, com seu império marítimo), veio a sofrer uma mudança gradual e, de uma perspectiva pedagógica, passou a ganhar uma inflexão cada vez mais rígida, à medida que seu imperialismo já não conseguia mascarar a necessidade de empregar a violência pura e simples para se manter enquanto tal. ${ }^{11}$ Nesse sentido, não é um acaso que quanto mais a França recorria a Atenas para defender uma imagem livre e democrática de sua Terceira República, tanto mais os autores britânicos sentiam a necessidade de colocar Esparta como o modelo ideal para a educação de um império vitorioso. Veja-se o que afirma Kenneth Freeman (1907, p. 284), em seu importante estudo, Schools of Hellas [Escolas da Hélade]:

[A] educação também tinha que consultar a felicidade das crianças, tanto quanto a felicidade da comunidade, embora em menor grau. Isso pode parecer uma declaração surpreendente para se fazer no que diz respeito à educação espartana. Contudo, acredito ser estritamente verdadeira. Deve ser lembrado que todos os relatos dos rigores e horrores dos métodos espartanos vêm de autores atenienses que certamente nunca tinham estado na Lacedemônia. Xenofonte, que teve seus filhos educados lá, oferece um relato muito mais brando e totalmente elogioso. 0 visitante ático, algo hedonista, deve ter observado os jogos e exercícios espartanos com muito

are clearly derived from the ancient sources, and sometimes from a sort of 'fiction' created by variant readings or misreadings of the ancient texts. [...] Finally, we can see this use of the Spartan paradigm above all as a practical application of that philhellenism which had flowered in PrussiaGermany since the late eighteenth century. Here, far from its habitual preserves of salon and study, enthusiasm for Greek ideals could usefully be applied to the everyday problems of barracks and battlefield." (ROCHE, 2012, p. 33-34).

10- Tradução minha. No original: "L'histoire d'Athènes, d'un bout à l'autre, n'est qu'un long et splendide triomphe de la jeunesse. Avec ces sentiments, les Athéniens ne pouvaient astreindre l'enfant à la sévère discipline qu'on lui imposait ailleurs, et ni dans les études ni dans la conduite, ils n'exigeaient de lui une obéissance qu'ils jugeaient incompatible avec son caractère. C'est ce qui fait que l'éducation nous apparaît, chez eux, empreinte d'une telle douceur. L'écolier travaille, mais librement; ses maîtres se contentent de lui indiquer ce qu'il doit faire: à lui de s'y exercer. Ni la palestre ni l'école ne sont pour lui de sombres prisons où l'on est tenu d'accomplir, dans un temps donné, une tâche fixe." (GIRARD, 1889, p. 331). 11- Para uma discussão sobre a forma como a universidade inglesa e seu discurso se constituíram nesse período, visando uma justificativa cultural para seu imperialismo, conferir Readings, 1996, p. 70-88. 
dos sentimentos que tem um francês ao visitar uma escola pública inglesa; ele considera difícil imaginar que os garotos se submeteram a tais rigores por escolha própria. Então devemos lembrar o que eram de fato os garotos espartanos. (FREEMAN, 1907, p. 284). ${ }^{12}$

Explorando diretamente a comparação entre um francês e um ateniense, em contraposição a um inglês e um espartano, Freeman propõe o mesmo tipo de crítica anteriormente visto com Girard ao modelo educacional adotado na Europa: parece-lhe necessário que a educação diga respeito a questões do interesse dos estudantes, tal como ele afırma ter sido entre os povos helênicos, de modo a que a afeição pelo estudo seja um dos principais motores do aprendizado (FREEMAN, 1907, p. 285). Ainda que esteja ciente das diferenças consideráveis entre a aplicação de um modelo educacional restrito a algumas centenas de crianças (como certamente era o caso em todas as póleis antigas analisadas por ele, como Atenas, Esparta e Creta) e o desafio educacional que diz respeito a uma educação de âmbito nacional - para milhares de futuros cidadãos adultos -, Freeman $(1907$, p. 289) defende que o modelo antigo ainda seria efetivamente capaz de inspirar e direcionar aquilo que ele entende como o mais efetivo e democrático modelo educacional britânico.

Na conclusão de seu estudo, depois de afirmar que “[o] objeto da educação helênica era produzir esse tipo de cidadão - um homem capaz de governar, lutar e estabelecer o gosto e os padrões de seu país", ${ }^{13}$ ele defende o seguinte:

Então as escolas da Hélade correspondem na Inglaterra não às escolas nacionais, mas às "escolas públicas". Eu não quero dizer que o garoto inglês da escola pública alcança, em sua vida futura, a posição de um cidadão helênico para a maior parte da população. A democracia inglesa apoiase em uma base mais ampla do que a ateniense ou a florentina e, pelo menos em teoria, o poder exclusivo das "classes elevadas" está no fim. Ainda assim, é verdade que dos garotos educados nas escolas públicas vem uma parte considerável dos generais e oficiais militares, do clero, dos escudeiros, dos juízes de paz e outros administradores da lei, dos governadores e oficiais requeridos pelo Império das Índias e pelas várias dependências e Colônias da Coroa, dos membros do Parlamento e políticos do Estado. (FREEMAN, 1907, p. 291). ${ }^{14}$

\footnotetext{
12- Tradução minha. No original: "[E]ducation had also to consult the happiness of the children as well as the happiness of the community, although in a lesser degree. This may seem a startling statement to make with regard to Spartan education. Nevertheless, I believe it to be strictly true. It must be remembered that all our accounts of the rigours and horrors of Spartan methods come from Athenian writers who in all probability had never been to Lakedaimon. Xenophon, who had his sons educated there, gives a much milder, and wholly eulogistic, account. The somewhat hedonistic Attic visitor must have watched Spartan games and exercises with much the feelings of a French visitor at an English public school; he found it difficult to realise that the boys underwent such hardships of their own free will. Then we must remember what the Spartan boys were." (FREEMAN, 1907, p. 284).

13- Em tradução. No original: "The object of Hellenic education was to produce this type of citizen - a man capable of governing, of fighting, and of setting the taste and standards of his country."

14- Em tradução. No original: "Thus the schools of Hellas correspond in England not to the national schools, but to the "public schools." I do not mean to assert that the English public-school boy stands, in after life, in the position of the Hellenic citizen to the bulk of the population. English democracy rests on a wider basis than Athenian or Florentine, and, in theory at any rate, the exclusive power of the "upper classes" is at an end None the less it is true that from among the boys educated at the public schools comes a very considerable part of the generals and military officers, of the clergy, of the squires, of the Justices of the Peace and other administrators of the law, of the governors and officials required by the Indian Empire and the various dependencies and Crown Colonies, of the members of Parliament and statesmen at home."
} 
Como se vê, os classicistas que - entre o fim do século XIX e o início do XX - se voltaram para a questão da educação na Antiguidade preocupavam-se constantemente em propor e estabelecer um modelo pedagógico renovado a fim de atender às novas demandas de um Estado Nacional tanto industrializado quanto empenhado em uma corrida imperialista e armamentista feroz. Nesse sentido, a Alemanha oferece o mais evidente testemunho dessa tendência generalizada, pois o debate pedagógico que se desenrola nesse país é não apenas muito complexo, mas fundamental para que se compreenda o futuro da relação entre os estudos clássicos e a educação.

De maneira geral, é possivel afirmar ter havido certa tendência a um historicismo cientificista entre os principais classicistas alemães do fınal do século XIX, principalmente a partir e em torno à figura de Wilamowitz-Moellendorf, um dos maiores responsáveis por ampliar o movimento de historicização dos textos antigos, em uma tentativa de compreender a Antiguidade à luz de suas próprias especificidades (HÜBSCHER, 2016, p. 44-49). Essa relativa despolitização dos estudos clássicos na Alemanha - para empregar aqui o arranjo geral sugerido para a história moderna desses estudos segundo os termos de Hartog (2003) $)^{15}$ - talvez tenha resultado do fato de tais estudos filológicos não terem sido capazes de oferecer uma resposta convincente ao problema sobre a origem e a identidade desse Estado Nacional no século XIX. Essa é a conclusão do artigo de Hinnerk Bruhns (2005, p. 42), que parece bastante acertada. ${ }^{16}$ Ainda assim, à medida que as sensibilidades nacionais foram afloradas por disputas imperialistas - cujo ápice viria a ser justamente a eclosão da Primeira Guerra Mundial -, os estudiosos alemães vieram a se posicionar vigorosamente no que diz respeito à relação entre os clássicos e a necessidade de preparar os jovens para o momento presente.

0 historicismo totalizante de Wilamowitz conviveu tranquilamente desde suas primeiras obras e discursos com o mais sereno classicismo e a mais plena convicção no valor permanente dos conteúdos da Antiguidade clássica (CANFORA, 1980, p. 35-38). ${ }^{17} \mathrm{~A}$ esse respeito, não deixa de ser emblemática a frase de uma carta que o estudioso enviou - ainda no início de sua longa carreira, em 1883 - a seu professor, Hermann Usener: "A poesia antiga (e, naturalmente, a lei, a crença e a história) está morta: nossa tarefa é vivificá-la” (apud NORTON, 2008, p. 78). Ainda assim, no período da Primeira Guerra Mundial, o seu engajamento com as questões mais prementes para o governo prussiano ganhou um redirecionamento ainda mais prático:

15- Num parágrafo do fim de seu artigo, o autor comenta: "Pode-se, assim, ver sucederem-se no confronto com os antigos fases de politização e despolitização, que são como respirações de longa duração, com momentos de interferência, de embaralhamento ou de conflito aberto entre as duas tendências." (HARTOG, 2003, p. 153).

16- Encerrando seu artigo, a estudiosa afirma o seguinte: "Au cours de ce siècle qui séparait Bismarck et Guillaume II de Goethe, la question du passé 'national' et des origines de l'État allemand avait pris une importance de plus en plus grande. Le conflit entre des traditions antagonistes du Reich, les avatars du mouvement unitaire démocratique et la solution apportée par la force avaient pour corollaire que des traditions multiples et inconciliables furent mobilisées. Cette pluralité de traditions était l'expression paradoxale d'un manque de tradition. La nouvelle entité allemande n'avait pu s'inscrire dans aucune tradition existante, ni su en construire une qui aurait permis aux Allemands de s'identifier à ce nouvel État." (BRUHNS, 2005, p. 42).

17- Para algumas das suas atividades não acadêmicas, mas de difusão do ideal clássico na sociedade alemã da época, (cf. MARCHAND, 2015, p. 243; HÜBSCHER, 2016, p. 48-49). 
Wilamowitz lançou-se à escrita de discursos violentamente nacionalistas e conclamou tão vigorosamente ao alistamento que seu próprio filho, o acadêmico extremamente promissor para o estudo de tragédia grega, Tycho von Wilamowitz-Moellendorf, partiu imediatamente para o front oriental - apenas para morrer já em outubro de 1914. (MARCHAND, 2015, p. 253). ${ }^{18}$

Posteriormente, engajando-se em uma disputa acadêmica internacional, conhecida pelo nome de Krieg der Geister [Guerra dos espíritos], Wilamowitz assinou o infame e malfadado Aufruf an die Kulturwelt [Apelo ao mundo civilizado] - ou, como veio a ser conhecido, "Apelo dos 93", porque contou com a assinatura de 93 intelectuais da universidade alemã. Contudo, tal como demonstrado pelo detalhado artigo de Robert Norton (2008), o pior ainda estava por vir: insatisfeito com o resultado surtido por seus pronunciamentos anteriores, Wilamowitz redige com suas próprias palavras a famigerada Erklärung der Hochschullehrer des Deutschen Reiches [Declaração dos professores universitários do Império Alemão], reiterando a afırmação da terrivel identidade entre a cultura alemã - da qual já haviam sido explicitamente destacadas as figuras de Goethe, Beethoven e Kant - e o militarismo prussiano. Essa declaração, que viria a ser assinada por mais de quatro mil professores universitários alemães (NORTON, 2008, p. 90), começava com o seguinte parágrafo:

Nós, professores de universidades da Alemanha e institutos de ensino superior, servimos o estudo e produzimos uma obra da paz. Contudo, enche-nos de indignação que os inimigos da Alemanha, tendo a Inglaterra à frente, desejem - massivamente em nosso favor - polarizar o espírito do estudo alemão e aquilo que chamam de militarismo prussiano. No exército alemão, não há espírito diverso daquele do povo alemão, pois ambos são um só e nós pertencemos a ele. (WILAMOWITZ, 1914 apud NORTON, 2008, p. 96). ${ }^{19}$

Reafırmando enfaticamente a crença de que uma salvação da cultura europeia [Kultur Europas] dependeria de uma vitória do "militarismo" alemão [der deutsche "Militarismus"], essa declaração teve por resultado acirrar ainda mais a animosidade contra os alemães de forma geral. ${ }^{20}$ Ainda assim, Wilamowitz jamais voltaria atrás na postura política adotada nessa época e - mesmo tendo desfrutado de mais alguns anos de dedicação à Wissenschaft [ciência], produzindo obras de grande fôlego - manteve uma atitude sempre lamentosa sobre a destruição do mundo que ele conhecera antes da guerra. ${ }^{21}$

18- Em tradução. No original: "Wilamowitz threw himself into the writing of violently nationalist speeches, and so vigorously urged enlistment that his own son, the highly promising scholar of Greek tragedy Tycho von Wilamowitz Moellendorff, departed immediately for the eastern front - to die there already in October 1914."

19- Em tradução. No original: "Wir Lehrer an Deutschlands Universitaten und Hochschulen dienen der Wissenschaft und treiben ein Werk des Friedens. Aber es erfullt uns mit Entrüßtung, daß die Feinde Deutschlands, England an der Spitze, angeblich zu unseren Gunsten einen Gegensatz machen wollen zwischen dem Geiste der deutschen Wissenschaft und dem, was sie den preußischen Militarismus nennen. In dem deutschen Heere ist kein anderer Geist als in dem deutschen Volke, denn beide sind eins, und wir gehoren auch dazu."

20- A respeito da repercussão negativa e anti-germânica dessa querela, conferir Canfora, 1980, p. 41-48; Norton, 2008, p. 90-92; Marchand, 2015, p. 253).

21- Conforme Norton (2008, p. 92): "After the war and everything Wilamowitz had fought for had collapsed, he retreated back into scholarship work and became more prolific than ever, producing well over 200 works before he died in 1931. But he never renounced any of his war-time positions, nor did he conceal his bitterness and disappointment that, as he said in 1923: 'The world I knew was destroyed.'” 
A destruição desse mundo esteve intimamente relacionada à destruição física provocada pelo conflito, mas não se restringia a isso: na Alemanha, um dos impactos da derrota foi um aumento na insatisfação com o formato acadêmico tradicional, levando a um questionamento de suas bases e à adoção de medidas modernizadoras e democratizantes do ensino. ${ }^{22}$ As mudanças sociais acentuaram tal tendência, mas esse quadro era compreendido pelos classicistas como nefasto, tanto da perspectiva do novo tipo de estudante que se apresentava, quanto da perda de prestígio acadêmico da própria área (MARCHAND, 2015, p. 253). Essa crise das humanidades foi sentida de forma aguda por muitos dos filólogos alemães, que, em sua busca por uma solução, se voltaram para a mais jovem promessa do campo na Alemanha: Werner Jaeger. ${ }^{23}$

\begin{abstract}
Alçado à cátedra de filologia clássica da Universidade de Berlim em 1921 - então a mais prestigiosa cátedra da disciplina no mundo -, Jaeger assumia a tarefa de dar continuidade à atuação de seu antecessor, o célebre Wilamowitz, como figura de liderança na campanha pela preservação e fortalecimento dos estudos clássicos no sistema de ensino alemão, tanto nas escolas secundárias quanto nas universidades. Não se tratava de uma tarefa simples, visto que o filólogo respondia agora às demandas impostas pela nova e hostil realidade da recém-instaurada República de Weimar. (HÜBSCHER, 2016, p. 54).
\end{abstract}

A forma como Jaeger resolveu articular o ensino clássico com as novas exigências do presente foi por meio da ideia de um Humanismo renovado - que viria a ser chamado de Terceiro Humanismo, a partir daquele que teria sido o primeiro, no Renascimento italiano, e o segundo, com o Neuhumanismus de Winckelmann -, sugerindo a necessidade de articular o presente alemão com o "seu" passado helênico. Esse passado constituiria para Jaeger não apenas a arkhé da verdadeira cultura [Kultur], a única que o mundo jamais teria conhecido - segundo uma visão extremamente eurocêntrica que restringia aos povos europeus todo o desenvolvimento cultural de verdade (JAEGER, 2013 [1934], p. 5-6) -, mas seria responsável por renovar o poder espiritual dos próprios alemães no presente:

Talvez não tenhamos ganhado grande coisa em afirmar que os gregos foram os criadores da ideia de cultura, num tempo cansado de cultura e em que se pode considerar como sobrecarga essa paternidade. Mas o que hoje denominamos cultura não passa de um produto deteriorado, derradeira metamorfose do conceito grego originário. [...] 0 mundo grego não é só o espelho onde se reflete o mundo moderno na sua dimensão cultural e histórica ou um símbolo da sua autoconsciência racional. 0 mistério e deslumbramento originário cercam a primeira criação de seduções e estímulos em eterna renovação. Quanto maior é o perigo de até o mais elevado bem se degradar no uso diário, com tanto maior vigor sobressai o profundo valor das forças conscientes

22- Além disso, é de se considerar que - da perspectiva da educação militar - a derrota na guerra levou a uma reconsideração momentânea sobre a função modelar que o militarismo espartano exercia para a Alemanha. (Cf. ROCHE, 2012, p. 27).

23- Segundo Suzanne Marchand (2015, p. 254): "Seeking a Perseus who would rescue and restore the world of prewar bourgeois neoclassicism, Wilamowitz, together with many other academic classicists and Gymnasium teachers, turned to Werner Jaeger, a much younger, philosophically oriented philologist who seemed to have the right mix of linguistic bona fides, institutional piety, and semivitalist yearnings to evade the Kraken of democratizing reform." 
do espírito que se destacaram na obscuridade do coração humano e estruturaram, no frescor matinal e com o gênio criador dos povos jovens, as mais altas formas de cultura. (JAEGER, 2013 [1933], p. 6-7).

Ou seja, o filólogo alemão - seguindo a tendência anteriormente vista entre outros filólogos europeus do período, preocupados com a relação entre educação e estudos clássicos - propunha um retorno aos povos helênicos a fim de renovar os padrões culturais e pedagógicos de seu próprio tempo: apelando para algo que seria dado a ver a partir da dimensão histórica de desenvolvimento desses povos primordiais, Jaeger sugeria sua importância para o presente, pois tal experiência poderia ser vivenciada em sua essência supra-histórica (HÜBSCHER, 2016, p. 76). Em suas proposições, obviamente se faz notar o vocabulário vitalista de Dilthey, que, tal como sugerido pelo excelente estudo de Bruno Hübscher (2016), esteve entre as principais influências filosóficas para o desenvolvimento da concepção jaegeriana de Paideía. ${ }^{24}$

Ainda que o estudioso tenha atuado regularmente como professor universitário e palestrante na Alemanha ao longo dos quinze anos que se seguiram à sua nomeação para a cadeira de filologia clássica na Universidade de Berlim, em 1921, tentando divulgar e defender seu ideal educacional classicizante (MARCHAND, 2015, p. 254), a verdade é que seus esforços não obtiveram o sucesso almejado: mesmo tendo buscado angariar a simpatia do novo regime político alemão - i.e., do nazismo -, o tom e as propostas do filólogo foram considerados incapazes de contemplar o entusiasmo requerido pelos promotores dessa "revolução". ${ }^{25}$ Desiludido com a recepção conferida às ideias que ele defendia em seu livro e em suas apresentações, Jaeger abdica de sua cadeira na Universidade de Berlim e migra para os EUA em 1936, onde sua influência sobre o campo dos estudos clássicos se faria sentir ainda pelas próximas décadas, mesmo tendo voltado sua atenção para versões alternativas da paideía idealizada por ele, como se dá em suas leituras sobre Demóstenes e o cristianismo primitivo (MARCHAND, 2015, p. 256).

Muitas outras propostas foram desenvolvidas por classicistas europeus e estadunidenses desse período sobre a relação entre os estudos clássicos e uma educação para o presente. Ainda que a multiplicidade de propostas e abordagens pudesse ser revelada por meio de uma análise mais detalhada de muitas outras obras, acredito que uma tendência geral possa ser extraída desse breve panorama delineado aqui a partir de Paul Girard, Kenneth Freeman, Ulrich von Moellendorf-Wilamowitz e Werner Jaeger: recorrendo à antiguidade como alternativa às dificuldades impostas pela industrialização, bem como pela corrida imperialista e armamentista, esses classicistas propuseram renovar a educação presente por meio do caráter paradigmático que a formação dos antigos helênicos ganhava a partir de seus estudos. 0 resultado de nenhuma dessas propostas, contudo, foi capaz de entusiasmar as gerações futuras, depois de terem vivenciado os horrores dos conflitos mundiais - principalmente aqueles perpetrados pelo nazismo, durante a Segunda Guerra Mundial -, e as premissas dos estudos clássicos têm sido fundamentalmente questionadas

24- Não é possível remontar toda a complexidade do Terceiro Humanismo aqui. Para mais detalhes, conferir Hübscher (2016, p. 54-83). 25- Para mais detalhes do processo, conferir Hübscher (2016, p. 142-181). 
desde o fim da primeira metade do século XX. As perguntas então formuladas a esses estudiosos continuam pertinentes até hoje: os estudos clássicos ainda têm alguma significância para o presente? Se sim, de que forma articular esses estudos sobre o passado com a realidade contemporânea? E como a questão da educação na era digital poderia se beneficiar de tais estudos?

Tal como sugerido por Eric Adler (2016, p. 218-225), num estudo recente sobre a crise das clássicas no ensino superior estadunidense - crise detectável a partir de uma queda no número percentual de matrículas, disciplinas, departamentos, professores e salários, em conformidade com uma tendência também testemunhada na França, na Inglaterra e na Alemanha -, é preciso que os classicistas se repensem e se organizem para oferecer respostas a algumas dessas justas questões que têm sido colocadas pela sociedade em geral. Afınal, diante da difícil história da forma como os estudos clássicos se prestaram aos mais diversos discursos sobre a educação, na linha do que o panorama aqui delineado pretendeu sugerir, de que modo as clássicas podem contribuir para a formação universitária ainda hoje? E o aprendizado de línguas clássicas? De que modo esses campos podem dar lugar a uma reflexão pedagógica renovadora e crítica?

0 desafio do classicista contemporâneo é dar prosseguimento a suas pesquisas e atividades docentes, tendo sempre em mira formular uma ou mais respostas contundentes a esses questionamentos. Seja articulando a dimensão multidisciplinar dos estudos clássicos, seja enfatizando sua importância para a constituição de nossos valores intelectuais, socioculturais e éticos, o importante é que os próprios classicistas venham a tomar um posicionamento claro diante disso tudo. Cumpre abrir mão do jargão elitista e da atitude academicista, propondo textos e cursos acessíveis e instigantes a um público mais amplo e diversificado, de modo a reanimar o interesse da população em geral por esse tipo de estudo. Do contrário, o futuro dessa área pode estar ameaçado e - o que é pior - pode ser que tal ameaça apresente razões justas para vir a se concretizar.

\section{Referências}

ADLER, Eric. Classics, the culture wars, and beyond. Ann Arbor: University of Michigan Press, 2016.

BRUHNS, Hinnerk. Grecs, Romains et Germains au XIXe siècle: quelle Antiquité pour l'État national allemand. Anabases, Toulouse, v. 1, p. 17-43, 2005.

CANFORA, Luciano. Ideologie del classicismo. Torino: Piccola Biblioteca Einaudi, 1980.

CONSTANT, Benjamin. CEuvres politiques. Paris: Charles Louandre, 1874.

FREEMAN, Kenneth. Schools of hellas: an essay on the practice and theory of ancient Greek education from 600 to 300 B.C.. London: Macmillan, 1907.

GIRARD, Paul. L'éducation athénienne au V ${ }^{\mathrm{e}}$ et au IV ${ }^{\mathrm{E}}$ siècle avant J.-C: ouvrage couronné par l'académie des inscriptions et belles-lettres. Paris: Librairie Hachette, 1889. 
HARDWICK, Lorna; STRAY, Christopher. A companion to classical receptions. Malden; Oxford; Carlton: Blackwell, 2008.

HARTOG, François. 0 confronto com os antigos. In: HARTOG, François. Os antigos, o passado e o presente. Org. José Otávio Guimarães; trad. Sonia Lacerda, Marcos Veneu e José Otávio Guimarães. Brasília, DF: Universidade de Brasília, 2003. p. 113-154.

HIGHET, Gilbert. The classical tradition: Greek and Roman influences on Western literature. New York; Oxford: Oxford University Press, 1976 [1949].

HÜBSCHER, Bruno. Werner Jaeger e o "Terceiro Humanismo": o ideal político antigo na Alemanha, 19141936. 2016. 236f. Tese (Doutorado em História Social) - Faculdade de Filosofia, Letras e Ciências Humanas da Universidade de São Paulo, São Paulo, 2016.

JAEGER, Werner. Paideia: a formação do homem grego. Trad. Artur M. Parreira. 6. ed. São Paulo: WMF Martins Fontes, 2013 [1933-46].

MARCHAND, Suzanne. The Great War and the Classical World: GSA Presidential Address, Kansas City, 2014. German Studies Review, Baltimore, v. 38, n. 2, p. 239-261, 2015.

NORTON, Robert. Wilamowitz at War. International Journal of the Classical Tradition, Berlin, v. 15, n. 1, p. 74-97, 2008.

READINGS, Bill. The university in ruins. Cambridge (MA); London: Harvard University Press, 1996.

ROBESPIERRE, Maximilien de. CEuvres de Robespierre. Texte établi par A. Vermorel. Paris: F. Cournol, 1867.

ROCHE, Helen. "Go, tell the Prussians...": The Spartan paradigm in Prussian military thought during the long nineteenth century. New Voices in Classical Reception Studies, Milton Keynes, n. 7, p. 25-39, 2012.

WILAMOWITZ-MOELLENDORF, Ulrich von. Reden aus der Kriegszeit: Krieges Anfang; Die geschichtlichen Ursachen des Krieges; Kriegserinnerungen; Militarismus und Wissenschaft; Heroentum. Berlin: Weidmannsche Buchhandlung, 1914-15.

WILAMOWITZ-MOELLENDORF, Ulrich von. Reden und Vorträge. Berlin: Weidmannsche Buchhandlung, 1901.

Recebido em: 05.08.2018

Aprovado em: 12.02.2019

Rafael Guimarães Tavares da Silva é estudante de língua e literatura clássicas (grego antigo) pela UFMG, com interesses que vão da filosofia (antiga e contemporânea) à teoria da literatura, além de teoria e prática da tradução. 